\title{
Análise histórica da contaminação de solo no município de Itabira/MG
}

Em decorrência do significativo avanço tecnológico nos últimos tempos, o processo de urbanização tem sido cada vez mais intenso. $O$ aumento das atividades acentuou a geração de compostos químicos, que descartados de maneira incorreta podem contaminar o meio ambiente, incluindo os solos. $\mathrm{O}$ objetivo deste trabalho foi avaliar, através do inventário de áreas contaminadas, disponibilizado pela Fundação Estadual do Meio Ambiente (FEAM), o processo de contaminação do solo no município de Itabira-MG, no período de 2009 a 2019, identificando as fontes de contaminação e os tipos de contaminantes, sendo observados seus comportamentos em decorrência da geologia e da pedologia do município. Através da utilização de dados espaciais fornecidos pelo IDE-Sisema, foram elaborados mapas temáticos sobre a geologia e pedologia da área de estudo e calculado a velocidade do fluxo da água subterrânea por meio do cálculo do gradiente hidráulico. Os tipos de contaminantes encontrados foram os hidrocarbonetos (80\%) e metais pesados (20\%) oriundos de postos de combustíveis, atividades de mineração e da deposição de resíduos dentro de Itabira-MG. Atualmente há quatro áreas no cadastro de áreas contaminadas da FEAM. A velocidade de propagação de contaminantes é relativamente baixa, visto que o valor do gradiente hidráulico, responsável pela velocidade do fluxo da água subterrânea, foi de $1,27 * 10^{-3} \frac{\mathrm{m}}{\mathrm{m}}$. Foi constatado que a geologia e a pedologia das áreas de estudo não favorecem a propagação de contaminantes.

Palavras-chave: Contaminação de solo; Geologia e Pedologia; Tipos de contaminantes; Fontes de contaminação.

\section{Historical analysis of soil contamination in the municipality of Itabira/MG}

\begin{abstract}
As a result of significant technological advances in recent times, the urbanization process has been increasingly intense. The increase in activities has accentuated the generation of chemical compounds, which incorrectly disposed of can contaminate the environment, including soils. The objective of this study was to evaluate, through the inventory of contaminated areas, made available by the State Environment Foundation (FEAM), the process of soil contamination in the municipality of Itabira-MG, in the period from 2009 to 2019, identifying the sources of contamination and the types of contaminants, with their behavior being observed due to the geology and pedology of the municipality. Through the use of spatial data provided by IDE-Sisema, thematic maps were prepared on the geology and pedology of the study area and the groundwater flow velocity was calculated by calculating the hydraulic gradient. The types of contaminants found were hydrocarbons $(80 \%)$ and heavy metals $(20 \%)$ from gas stations, mining activities and the deposition of waste within Itabira-MG. There are currently four areas in the FEAM contaminated area register. The propagation speed of contaminants is relatively low, since the value of the hydraulic gradient, responsible for the groundwater flow speed, was $1,27 * 10^{-3} \frac{\mathrm{m}}{\mathrm{m}}$. It was found that the geology and pedology of the study areas do not favor the spread of contaminants.
\end{abstract}

Keywords: Soil contamination; Geology and Pedology; Types of contaminants; Contamination sources.

Topic: Desenvolvimento, Sustentabilidade e Meio Ambiente

Reviewed anonymously in the process of blind peer.
Received: 03/03/2021 Approved: 26/03/2021
Cristhian Filgueira Dias (10)

Universidade Federal de Itajubá, Brasil http://lattes.cnpq.br/7525610658441198 http://orcid.org/0000-0002-2818-6463 cristhiandias3@gmail.com

Fernanda Maria Belotti iD

Universidade Federal de Itajubá, Brasil http://lattes.cnpq.br/5777360077113950 http://orcid.org/0000-0003-3417-3738

fernandabelotti@unifei.edu.br
Referencing this:

DIAS, C. F.; BELOTTI, F. M.. Análise histórica da contaminação de solo no município de Itabira/MG. Revista Ibero Americana de Ciências Ambientais, v.12, n.3, p.502-515, 2021. DOI: http://doi.org/10.6008/CBPC2179-6858.2021.003.0041 


\section{INTRODUÇÃO}

Os últimos dois séculos foram marcados por avanços tecnológicos como jamais vistos anteriormente na história das civilizações. Tais avanços permitiram grandes mudanças no que tange aos meios de produção e consumo, gerando, assim, significativo progresso e desenvolvimento nos estilos de vida das sociedades. Entretanto, o progresso econômico e tecnológico não foi acompanhado de uma preocupação acerca dos impactos que as atividades desenvolvidas poderiam acarretar ao meio ambiente.

Com o aumento das atividades humanas no passar dos anos houve uma intensificação na geração de compostos químicos, que, descartados de forma inadequada, contaminam o meio ambiente. $\mathrm{O}$ descarte de compostos recalcitrantes afeta solos, cursos d'água e a atmosfera, tornando-os cada vez mais degradados. A degradação desses meios, com ênfase nos solos, que é comumente empregado para o descarte de poluentes, gera malefícios que impedem, muitas vezes, a prospecção da vida e, por isso, se torna cada vez mais necessário entender e buscar formas que amenizam os impactos gerados pelo desenvolvimento desordenado (ANTENOR et al., 2020).

O solo consiste em um elemento natural fundamental para a vida no planeta. É formado por sólidos, líquidos e vapores e é capaz de abrigar inúmeros ecossistemas, servindo também de reservatório de água e nutrientes, sendo de extrema relevância para os ciclos naturais, como o hídrico. Segundo a FAO, cerca de $33 \%$ dos solos globais estão degradados e aproximadamente 10 milhões de pessoas abandonaram seus países de origem em razão de tal desgaste. Outro problema é a contaminação de águas subterrâneas através da percolação dos contaminantes no solo, uma vez que os aquíferos subterrâneos constituem o maior volume de água doce líquida disponível na Terra.

A Política Nacional do Meio Ambiente (lei de $n^{\circ}$ 6.939/1981) define poluição de solo como qualquer alteração nas características físicas, químicas e biológicas que acarreta em prejuízos à saúde, à segurança, ao bem-estar da população, podendo ainda comprometer a biota e a utilização dos recursos para fins comerciais, recreativos e industriais. Desta forma, solos contaminados, podem acarretar em poluição ${ }^{1}$, e seus consequentes malefícios.

As fontes de contaminação são inúmeras, podendo ser pontuais ou sazonais, e o grau de degradação, seja ela física ou química, permanente ou temporária, varia de acordo com o tipo de contaminante e o comportamento deste no ambiente em questão. Dentre os contaminantes, alguns dos tipos mais comuns são os hidrocarbonetos e os metais pesados. Desta maneira, a presença de compostos recalcitrantes, como metais pesados, hidrocarbonetos, substâncias inorgânicas têm sido descritas em diversos contextos como de extrema importâncias e evitar diversos problemas, desde problemas voltados à saúde pública quanto a degradação ambiental (BERNARD, 1997; ACCIOLY et al., 2000).

Os hidrocarbonetos são compostos derivados do petróleo e a sua utilização surge com o desenvolvimento das cidades. Fogaça et al. (2014) dizem que há uma proporcionalidade nessa relação. 0

\footnotetext{
${ }^{1}$ Poluição é uma alteração ecológica que afeta a relação entre os seres vivos, provocada por ação antrópica, prejudicando, direta ou indiretamente, o bem estar social, ocasionando danos aos recursos naturais. Entretanto contaminação é a presença de patógenos que provocam doenças, ou substâncias em concentrações nocivas aos seres humanos, sem que haja alteração ecológica ao longo do tempo. Sendo assim, uma área contaminada só se torna poluída caso ocorra uma alteração ecológica com o passar do tempo (NASS, 2002).
} 
armazenamento inadequado destes poluentes, seja em postos de combustíveis ou oleodutos, pode ocasionar vazamentos, sendo uma das formas de contaminação dos solos por esses compostos.

Buscando entender como se dá o comportamento desses poluentes no solo, alguns autores afirmam que as fases dos contaminantes classificados como hidrocarbonetos podem ser: fase livre, fase dissolvida, fase vaporizada, fase condensada e fase adsorvida, sendo esta última uma das mais difíceis de se remediar.

Já os metais pesados podem ter origem natural, isto é, podem ser provenientes da composição rocha de formação do solo, da composição da fase sólida do solo, bem como dos seus processos de intemperismo (ABREU et al., 2002). Lange et al. (2002) demonstram que há uma complexidade na interação do solo com os metais pesados, uma vez que diversas reações podem ocorrer simultaneamente.

As fontes antrópicas de contaminação por metais pesados podem ser diversas, como, por exemplo, atividades de mineração. A extração dos minérios implica na supressão da vegetação e na retirada do solo fértil, deixando expostos os horizontes mais profundos, com possibilidade de erosão, assoreamento dos corpos hídricos próximos e percolação dos metais pesados no solo (MECHI et al., 2010).

Outra fonte de contaminação se dá através da lixiviação de chorume proveniente de aterros sanitários. Segundo Costa (2008), o chorume é rico em água com sais minerais, matéria orgânica e metais pesados, portanto, a infiltração desse lixiviado acarreta a poluição dos solos e das águas subterrâneas.

Os mecanismos básicos de transporte de contaminantes são a advecção, dispersão mecânica e a dispersão molecular, sendo estas subdivisões da dispersão hidrodinâmica. A advecção provoca a dispersão do soluto devido ao fluxo hidráulico do fluído em que este se encontra dissolvido. Vale ressaltar que no transporte advectivo o soluto não interage com o meio poroso. Em contrapartida, a dispersão hidrodinâmica consiste num espalhamento do fluido além da trajetória prevista (OLIVEIRA, 2002).

A contaminação de solos por metais pesados e hidrocarbonetos é algo recorrente em ambientes urbanos. Neste contexto, é inegável a relevância dos impactos ambientais causados por intensas atividades humanas em cidades brasileiras, com especial atenção ao cenário delineado em Itabira, no Estado de Minas Gerais.

Portanto, através de uma análise histórica será possível identificar os solos contaminados no referido município, identificar os tipos e as fontes de contaminação, indicar quais áreas são mais suscetíveis à propagação dos contaminantes de acordo com o tipo de solo e geologia da região e, portanto, priorizar as áreas que necessitam de intervenção e monitoramento.

\section{MATERIAIS E MÉTODOS}

\section{Área de estudo}

O município de Itabira está localizado na região central de Minas Gerais, também conhecida como Quadrilátero Ferrífero², próximo à capital mineira, Belo Horizonte. Segundo censo do IBGE (2010), Itabira abriga cerca de 120.000 mil habitantes, com uma extensão territorial de 1.253,704 km², possuindo bioma de 
transição entre o cerrado e a mata atlântica e um relevo majoritariamente montanhoso. O município está inserido na Bacia do Rio Piracicaba, sendo uma sub-bacia do Rio Doce, com um clima caracterizado na faixa tropical subquente, classificado com mesotérmico brando, com meses chuvosos de novembro a janeiro, e meses de estiagem de junho a agosto.

Os primeiros registros de Itabira datam em torno de 1700 e retratam a existência de ouro de aluvião que atraiu exploradores, em busca da riqueza mineral presente na região. Assim, desde o começo de sua história há extração de minérios, sobretudo o minério de ferro, consolidada com a fundação da empresa Vale em 1942, cuja atividade é responsável por grande parte do PIB da cidade (VALE, 2020). O PIB per capita do município no ano de 2017 foi de $R \$ 43.763,91$, sendo que o setor industrial alcançou a 10a posição em Minas Gerais no mesmo ano.

\section{Levantamento de histórico de áreas contaminadas e elaboração de gráficos}

O estudo deste trabalho é de natureza quantitativa, consistindo no levantamento de dados secundários disponibilizados pela Fundação Estadual do Meio Ambiente (FEAM), no período de 2009 a 2019 (FEAM, 2020). O levantamento de dados quantitativos refere-se à identificação e quantificação das áreas contaminadas, tipo de atividade que ocasionou a contaminação, bem como ao percentual dos tipos de contaminantes. A partir de tais dados foram elaborados os seguintes gráficos: progressão das áreas contaminadas em Itabira/MG, fontes de contaminação e tipos de contaminantes, com a utilização da ferramenta Excel, no intuito de estabelecer um panorama da contaminação de solos dentro do município

\section{Elaboração de mapas temáticos de Pedologia e de Geologia}

As análises qualitativas têm o intuito de avaliar o comportamento dos contaminantes em relação à pedologia e geologia da área contaminada. Sendo assim, foram elaborados os mapas pedológico e geológico do município, a partir do recorte de dados disponibilizados pela Infraestrutura de Dados Espaciais do Sistema Estadual de Meio Ambiente e Recursos Hídricos. Foram plotadas as áreas contaminadas para permitir a identificação do tipo de solo e tipo de rocha existentes em tais áreas, para posterior avaliação do comportamento dos contaminantes em relação à pedologia e geologia. Tais dados espaciais, em relação

A pedologia, foram elaborados pela Universidade Federal de Viçosa e a FEAM (2017), já os dados espaciais, em relação à geologia, foram elaborados pela CODEMIG et al. (2017), ambos disponibilizados no webmap do IDE-SISEMA, na escala 1:1.000.000. Os mapas temáticos foram elaborados através do software QGIS 3.10.4 Corunã.

\section{Avaliação do comportamento dos contaminantes em relação à geologia e pedologia das áreas contaminadas}

De acordo com Pereira et al. (2011), as características dos solos, representadas por sua textura ou granulometria, que, segundo Lepsch (2010), refere-se à porcentagem de areia, silte e argila do solo, são fatores determinantes na previsão dos parâmetros de transporte de contaminantes. Além do mais, o teor de 
argila está intimamente ligado aos coeficientes de dispersão do contaminante no solo (PEREIRA et al., 2011).

Levando em consideração a geologia, Azevedo (2005) diz que a permeabilidade e a porosidade das rochas são fundamentais para a remediação das áreas contaminadas. A porosidade consiste numa medida adimensional para calcular os espaços vazios (poros, fraturas ou fissuras) num determinado volume de material. Em contrapartida, a permeabilidade é o arranjo geométrico do material que define as características de transmissibilidade de um fluído no meio poroso.

A relação entre a geologia, pedologia e o risco de propagação de contaminantes foi determinada em decorrência da identificação da classificação geológica e pedológica nos pontos de contaminação. Para a pedologia foi identificada a textura das classes de solo encontradas e a relação da textura com os mecanismos de adsorção de contaminantes no solo, ou seja, a Capacidade de Troca de Cátions (CTC) e a Capacidade de Troca de Ânions (CTA). Para a geologia foi identificada a porosidade e a permeabilidade das rochas existentes nas áreas contaminadas. As características pedológicas foram levantadas a partir do Sistema Brasileiro de Classificação de Solos (EMBRAPA, 2018) e as características geológicas foram levantadas a partir do Serviço Geológico do Brasil.

\section{Determinação das cargas hidráulicas}

As cargas hidráulicas foram determinadas seguindo a metodologia de Heath (1982), onde através das características de poços conhecidos, pode-se determinar o sentido do fluxo de contaminantes e o gradiente hidráulico, que descreve a velocidade com que a água subterrânea se movimenta, por meio de um arranjo triangular.

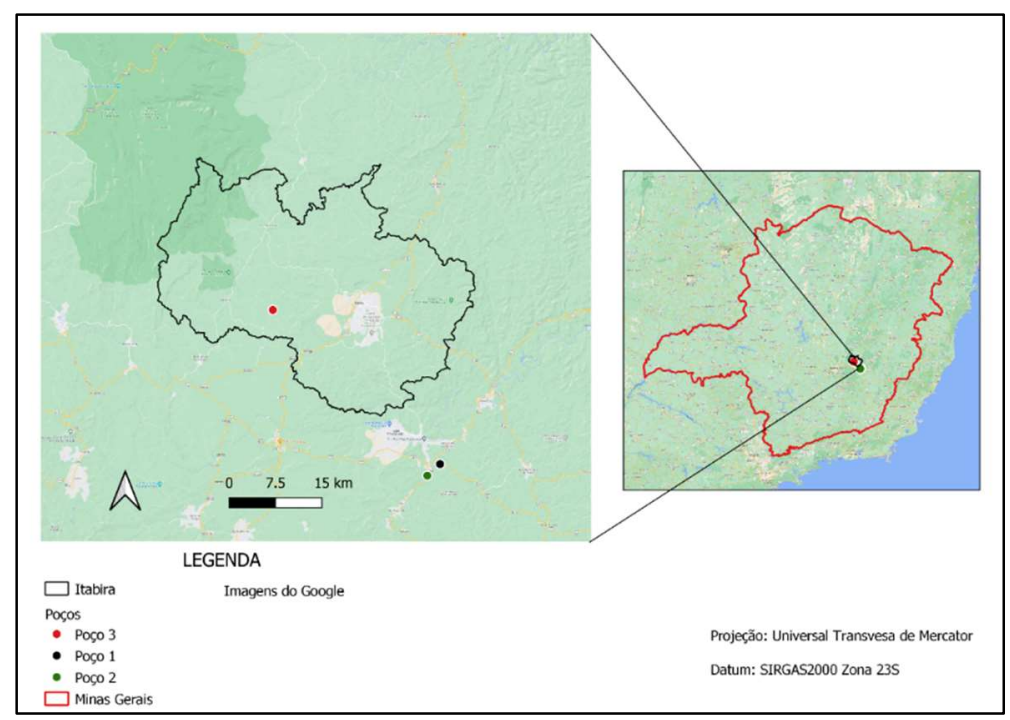

Figura 1: Localização dos poços para a determinação das cargas hidráulicas.

Para isso, foram utilizados dados do SAAE - Itabira (2020) e do Siagas WEB, onde foram coletadas as profundidades, as cotas e os níveis d'água de três poços distintos demonstrados na Figura 1. Através do Google Earth (2020) foi possível obter a distância entre os poços e visualizar cada um deles. O arranjo triangular foi determinado mediante a obtenção dos dados necessários sendo considerada a proximidade com as áreas de estudo. Os poços selecionados estão inseridos dentro dos municípios de Itabira e João 
Monlevade.

Com o intuito de determinar o sentido do fluxo da pluma de contaminantes e o gradiente hidráulico, que demonstra a velocidade do fluxo de contaminantes dentro do município de Itabira-MG, foram levantados os dados descritos na Tabela 1.

Tabela 1: Dados dos poços selecionados.

\begin{tabular}{ccccccc}
\hline Poços & $\begin{array}{c}\text { Cota do poço Profundidade do poço } \\
(\mathrm{m})\end{array}$ & $\begin{array}{c}\text { Nível d'água } \\
(\mathrm{m})\end{array}$ & $\begin{array}{c}\text { Carga de } \\
\text { Posição } \\
(\mathrm{m})\end{array}$ & $\begin{array}{c}\text { Carga de } \\
\text { Pressão } \\
(\mathrm{m})\end{array}$ & $\begin{array}{c}\text { Carga } \\
\text { Hidráulica } \\
\text { Total }(\mathrm{m})\end{array}$ \\
\hline 1 & 648 & 80 & 40,35 & 607,65 & 0 & 607,65 \\
2 & 636 & 120 & 32 & 604 & 0 & 604 \\
3 & 686 & 61 & 4 & 682 & 0 & 682 \\
\hline
\end{tabular}

O cálculo do gradiente hidráulico foi feito através da seguinte Equação 1:

$$
\frac{H l}{L}=\frac{\left(h r_{1-} h r_{2}\right)}{L}
$$

Onde:

$$
\begin{array}{cl}
\frac{H l}{L} \text { : gradiente hidráulico; } & h r_{1} \text { : carga hidráulica total do poço 1; } \\
L \text { : distâncias entre os dois poços; } & h r_{2} \text { : carga hidráulica total do poço 2; }
\end{array}
$$

A distância entre o poço 1 e o poço 2 foi de $2,86 \mathrm{~km}$, sendo medida através da ferramenta distância entre dois pontos do Google Earth. Sendo assim, foi possível determinar as cargas hidráulicas totais de cada poço, bem como o sentido fluxo e o gradiente hidráulico.

\section{RESULTADOS E DISCUSSÃO}

\section{Histórico de áreas contaminadas}

A análise quantitativa de dados levantados permitiu identificar um total de quatro áreas contaminadas no município de Itabira-MG, no período de 2009 a 2019, sendo identificadas as seguintes áreas: Posto de Combustível Araújo (área 1); Depósito de resíduo sólido e urbano de Itabira (área 2); Posto de Combustível Campestre (área 3); Estação Ferroviária Laboreaux, Estrada de Ferro Vitória a Minas (área 4) (FEAM, 2020).

A Figura 2 demonstra a totalidade de áreas contaminadas dentro do município de Itabira-MG no decorrer dos anos. Nos anos de 2009 e 2010 o município possuía apenas uma área cadastrada como contaminada (área 4 - Estação Ferroviária Laboreaux). A partir de 2011 houve um aumento no número de áreas contaminadas, com cadastro de três áreas contaminadas no período de 2012 a 2015 (área 2 - depósito de resíduo sólido e urbano de Itabira; área 3 - posto de combustível Campestre; área 4 Estação Ferroviária Laboreaux). Em 2016, de acordo com a FEAM (2020), houve um decaimento no número de áreas contaminadas, isto se deve ao fato de que houve a recuperação dá área 4. Entretanto, em 2017 houve um novo foco de contaminação, reinserindo a área no cadastro, além do surgimento de uma nova área contaminada (área 1 - posto de combustível Araújo). Por fim, em 2019, concretizou um total de quatro áreas 
contaminadas dentro do município, sendo duas áreas com postos de combustíveis, uma área de depósito de resíduos e uma área de estação ferroviária.

As quatro áreas estão classificadas como: área reabilitada para uso declarado (área 4); área em processo de monitoramento para a reabilitação (área 1; área 3); área sob investigação confirmatória (área 2) (FEAM, 2020).

Para entender como são classificadas as áreas contaminadas, a Deliberação Normativa Conjunta COPAM/CERH-MG (decreto de $n^{\circ} 2 / 2010$ ), caracteriza área contaminada sob investigação como "aquela em que for comprovadamente constatada, mediante Investigação Confirmatória, a contaminação com concentrações de substâncias químicas no solo ou nas águas subterrâneas acima dos valores de investigação". Já a área em processo de monitoramento para a reabilitação é caracterizada como "aquela em que for atingida a redução do risco aos níveis toleráveis, de acordo com as metas estipuladas na Avaliação de Risco" ou "não for caracterizada situação de perigo e não foi verificada situação de risco à saúde humana igual ou superior aos níveis aceitáveis de acordo com a Avaliação de Risco". E por fim, área reabilitada para uso declarado é caracterizada como "aquela em que, após período de monitoramento para reabilitação, seja confirmada a eliminação do perigo ou a redução dos riscos a níveis toleráveis para o uso declarado".

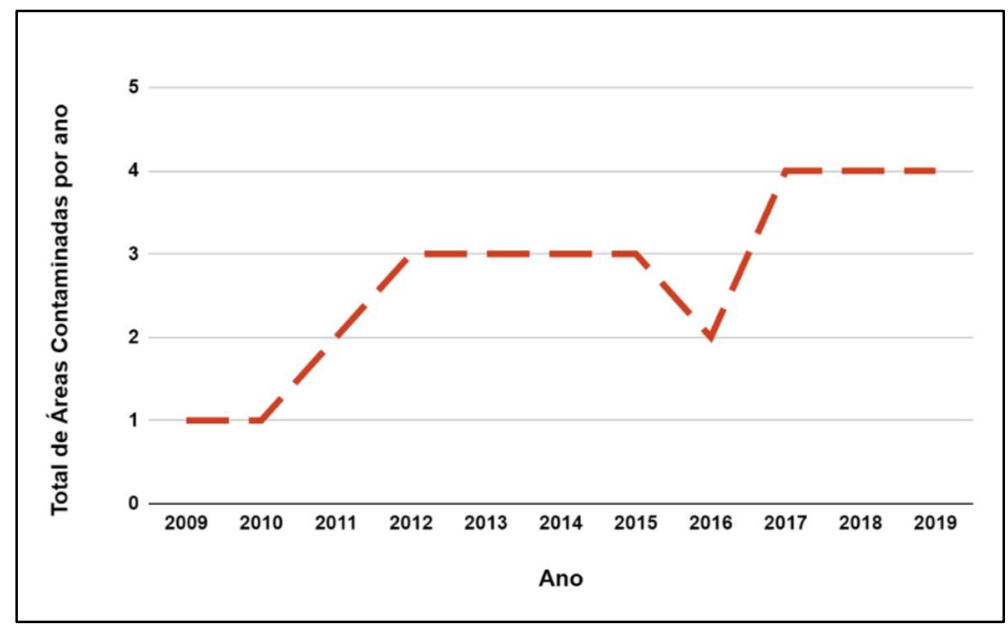

Figura 2: Progressão das áreas contaminadas em Itabira - MG no período de 2009-2019.

Na Figura 3 pode-se observar o percentual das fontes de contaminação encontradas no município, sendo que $20 \%$ procedem de aterro sanitário, $40 \%$ de postos de combustíveis na cidade e $40 \%$ de atividades de mineração. Já a Figura 4 apresenta os tipos de contaminantes que são: metais pesados (20\%) e hidrocarbonetos (80\%). Os metais pesados são oriundos da deposição de resíduos (área 2) e os hidrocarbonetos das atividades de mineração (área 4) e de postos de combustíveis (área 1 e área 3).

Os metais pesados mais comuns encontrados em zona urbana, segundo Madrid et al. (2002) são o cobre, chumbo e zinco e suas fontes podem ser diversas. De acordo com Celere et al. (2007) o chorume, líquido escuro que contém variadas substâncias orgânicas e inorgânicas, proveniente de aterros sanitários, é uma das fontes de contaminação em regiões urbanas, podendo conter altas concentrações de metais pesados, e por apresentar substâncias solúveis, há grande possibilidade de contaminar cursos d'águas superficiais, ou até mesmo se infiltrar no solo e atingir águas subterrâneas comprometendo as suas 
finalidades. Vale ressaltar que a composição do chorume é extremamente variável, estando ligado a fatores que vão desde as condições pluviométricas, tempo de disposição e até mesmo as características o próprio resíduo.

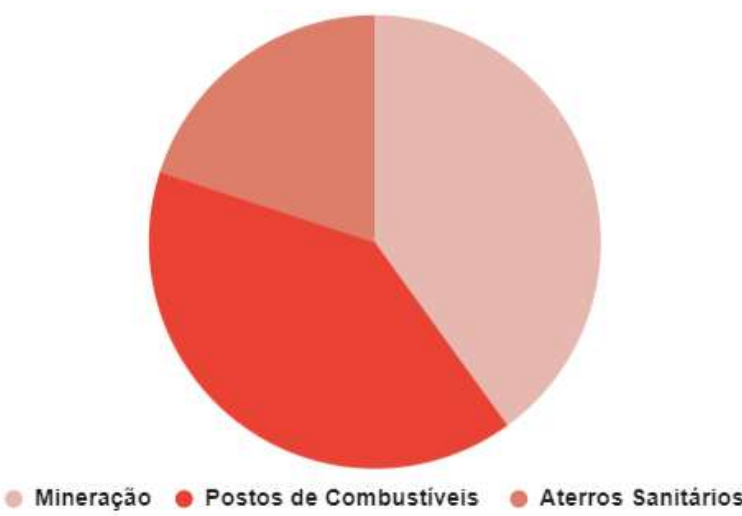

Figura 3: Fontes de contaminação em Itabira-MG no período de 2009-2019.

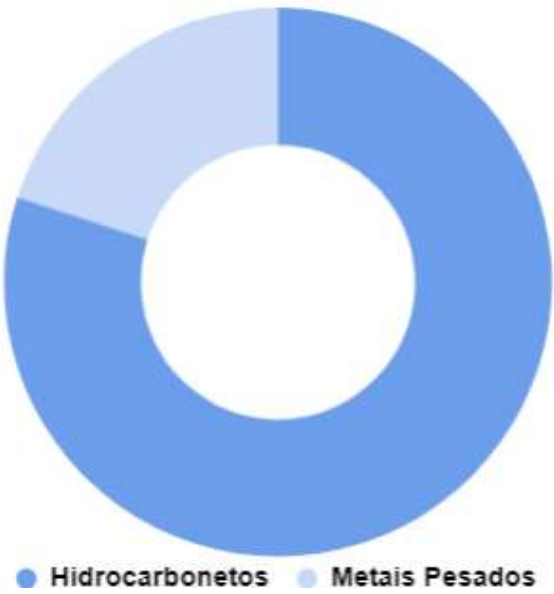

Figura 4: Tipos de contaminantes identificados em Itabira-MG no período de 2009-2019.

Em contrapartida, os hidrocarbonetos são compostos formados por hidrogênios e carbonos e Lima et al. (1998) afirmam que centros urbanos são locais com grande potencial de contaminação por esses compostos, devido ao fato de que além das atividades industriais que se pode ter nesses lugares, têm a presença de postos de combustíveis que podem contribuir para contaminar o ar, o solo, subsolo e águas subterrâneas como resultado de vazamentos dos tanques de armazenamento de combustíveis ou outros incidentes similares. Vale ressaltar que uma das principais preocupações é o comprometimento dessas águas subterrâneas, visto que são comumente utilizadas para o abastecimento humano (CUSTANCE et al., 1992)

Portanto, em decorrência dessas atividades e riscos associados à ocorrência de acidentes e/ou manuseio e armazenamento inadequado de substâncias potencialmente poluentes, grande parte destas substâncias podem atingir o solo, e em consequência do seu arranjo molecular, a baixa solubilidade em água e a predisposição de sorção à fase sólida do solo podem manter-se durante longos períodos no ambiente, acarretando um aumento da possibilidade de exposição dos seres vivos a esses hidrocarbonetos. E essa exposição a esses contaminantes, quando metabolizados no organismo, pode acarretar em diversos tipos de câncer.

\section{Cargas hidráulicas e comportamento de contaminantes em relação à pedologia e geologia das áreas contaminadas}

A partir dos cálculos realizados, o valor do gradiente hidráulico foi de: $1,27 * 10^{-3} \frac{\mathrm{m}}{\mathrm{m}}$. Heath (1982) observou que grande parte do movimento de água subterrânea é muito lento, com uma relação da taxa de troca entre água subsuperficial e água superficial de 1/9000, o que explica o valor baixo encontrado. Tais valores com ordem de grandeza $10^{-3}$ também foram encontrados por Celligoi et al. (2012) e Santos (2005).

Desta maneira, segundo a Lei de Darcy, a velocidade das águas subterrâneas está diretamente ligada ao gradiente hidráulico, vale ressaltar que esta lei se aplica apenas para escoamentos laminares, ou seja, há 
um escoamento suave pelos poros do aquífero (PEREIRA, 2000). O sentido do fluxo de contaminantes pode ser observado na Figura 5 e na Figura 6, apontando para a direção sudeste.

Considerando a classificação pedológica de Itabira-MG, identificada na Figura 5, a área contaminada sob investigação está inserida no Latossolo Vermelho Distroférrico (área 2 - depósito de resíduo sólido e urbano de Itabira), e as demais áreas, área reabilitada para uso declarado (Estação Ferroviária Laboreaux), área em processo de monitoramento para a reabilitação (ambos postos de combustíveis) no Latossolo Vermelho Distrófico.

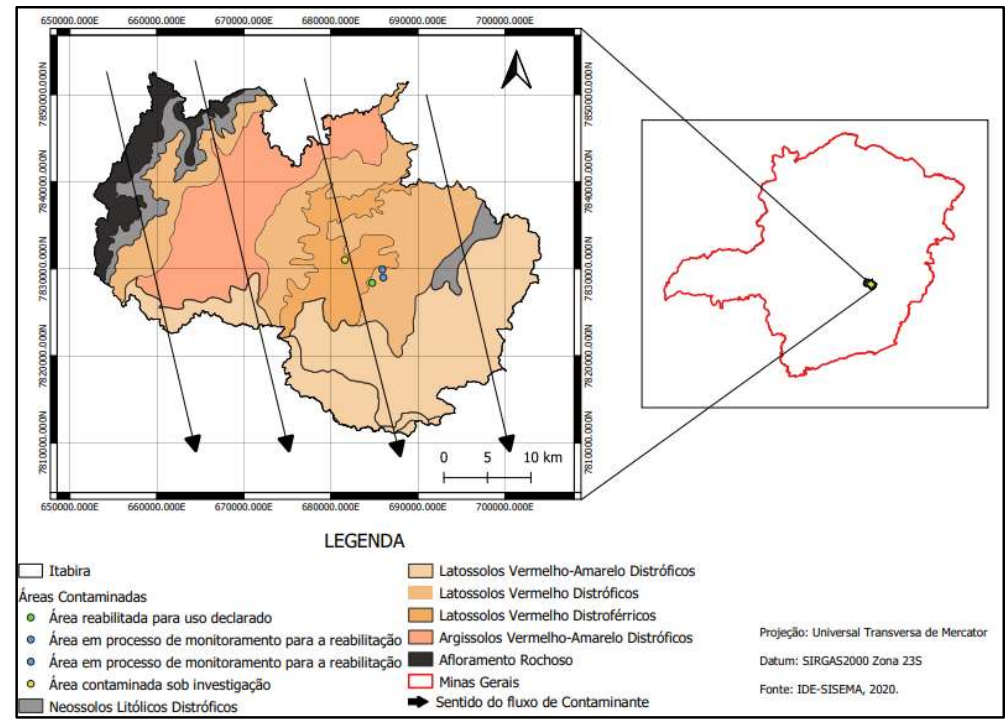

Figura 5: Classificação pedológica no município de Itabira-MG.

Segundo a EMBRAPA (2018) o que diferencia um Latossolo Vermelho Distrófico para um Latossolo Vermelho Distroférrico é a presença de ferro no segundo tipo de solo, com $180 \mathrm{~g} \mathrm{~kg}^{-1}$ a $<360 \mathrm{~g} \mathrm{~kg}^{-1}$, nos primeiros cem centímetros do horizonte B.

Latossolos são solos espessos, com horizonte B latossólico, podendo atingir três metros ou mais de profundidade, e sua coloração varia de acordo com teores de óxidos de ferro e alumínio. São solos bastante intemperizados, explícito pela transformação quase completa dos minerais originários, com baixa saturação por bases e baixa capacidade de troca de cátions (CTC), possuindo teores de argilas variáveis, que se mantém constantes ou aumentam gradativamente ao longo da profundidade, bastante permeáveis e com valores de pH elevados (EMBRAPA, 2018).

O fato de Latossolos terem baixa CTC, sendo menor que $17 \mathrm{cmol}_{c} \mathrm{~kg}^{-1}$ de argila, interferem na capacidade de reter cátions no solo, deixando de formar complexos de esfera-externa, que representa uma medida indireta da quantidade de cargas negativas presentes no solo, o que possibilita num espalhamento do contaminante no meio (EMBRAPA, 2018; MEAULO, 2004; MEURER, 2017). Porém, o valor de CTC está intimamente ligado ao valor de $\mathrm{pH}$ do solo, ou seja, o aumento do $\mathrm{pH}$ do solo, favorece o aumento da CTC, o que acarreta numa diminuição da mobilidade desses contaminantes nesse solo (SILVEIRA et al., 2003).

Outra característica desses solos é que possuem a capacidade de troca de ânions (CTA) mais significativa, sendo uma medida da capacidade do solo em reter ânions. Geralmente, solos bastante drenados, com um processo de intemperismo avançado, com acidez elevada, na presença de óxidos de ferro 
e alumínio, acarretam num balanço de carga positivo, como no caso dos solos estudados neste trabalho (LEPSCH, 2011).

Camago et al. (1997) demonstra que tanto a CTC quanto a CTA do solo estão ligados ao pH, onde em solos bastantes intemperizados, com quantidade elevada de óxidos e hidróxidos, ocorre uma alteração na relação de cargas positivas e negativas do solo. Tal afirmação é de grande relevância, pois pode demonstrar uma atenuação ou propagação do contaminante no meio.

Os solos estudados apresentam valores expressivos de óxidos de ferro, principalmente o Latossolo Vermelho Distroférrico. Esse fato demonstra uma capacidade desses solos em atenuar a mobilidade de poluentes, especialmente metais pesados. Isto é demonstrado por Alleoni et al. (2005) que descreve correlações positivas na interação dos metais pesados com os óxidos de ferro e alumínio presentes no horizonte B latossólico, acarretando numa baixa mobilidade desses compostos no solo. Oliveira et al. (2002) também atestou uma baixa mobilidade de metais pesados em Latossolos. Tal fenômeno pode ser explicado por Covelo et al. (2007) que verifica a adsorção desses elementos pelos óxidos de ferro da fração argila.

Meaulo (2004) demonstra que a atenuação e a migração de poluentes no solo agem de formas diferentes na presença ou ausência de água subterrânea, ou seja, os mecanismos são divergentes quando presentes na zona saturada ou insaturada. A zona insaturada reduz a presença de compostos orgânicos, sendo uma camada importante nesse processo, através da atividade microbiológica, oxidação, redução, volatilização, como ocorre com os hidrocarbonetos, que devido a sua estrutura, possuem baixa polaridade e solubilidade, fazendo com que uma parte se dissolva na solução do solo, uma parte fica retina nos espaços porosos do solo e outras partes volatizam (NADIM et al., 1999). Como os hidrocarbonetos estão presentes nas áreas 1, 3 e 4, oriundos de atividades de mineração e postos de combustíveis, sobre o Latossolo Vermelho Distrófico, parte desse composto fica retido, devido à elevada porosidade do solo e grande parte é evaporada, em razão da alta volatilidade dos hidrocarbonetos, como constatado por Chiaranda (2006). Já a zona saturada atua através da dispersão hidrodinâmica, fazendo com que o contaminante entre em equilíbrio com água subterrânea, acarretando numa diluição do mesmo no meio, fazendo com que esses compostos sejam carreados pelo perfil do solo. De modo geral, o carreamento é mais lento devido à velocidade da água na zona saturada, como demonstrado pelo gradiente hidráulico, e por serem solos profundos, dificulta o aumento da área de impacto por esses contaminantes. Vale considerar que as características do contaminante, como viscosidade, densidade, polaridade e afins devem ser levadas em consideração nas interações que ocorre soluto x solvente (MEAULO, 2004).

Sendo assim, o que se espera é que os Latossolos estudados se comportem como uma ferramenta de atenuação dos poluentes devido às suas características físico-químicas, dificultando a dispersão desses contaminantes no meio, ou que, caso ocorra essa dispersão, devido à porosidade e profundidade destes solos, essa dispersão seja mínima.

Em relação às características geológicas das áreas contaminadas, como pode ser observado na Figura 6, os tipos de rochas encontrados em cada área foram: área 1 sob filito, xisto, itabirito e dolomito, inseridas no Grupo Itabira; área 2 está sob granito, inserido na Suíte Borrachudos; área 3 e a área 4 sob filito, dolomito, 
quartzito e xisto, inserido no Grupo Piracicaba. Esses tipos de rochas são: rochas ígneas ${ }^{3}$ (área 1 e área 2), metamórficas ${ }^{4}$ (área 3 e área 4), sendo caracterizados como complexos cristalinos e metassedimento ou metavulcânicas, respectivamente.

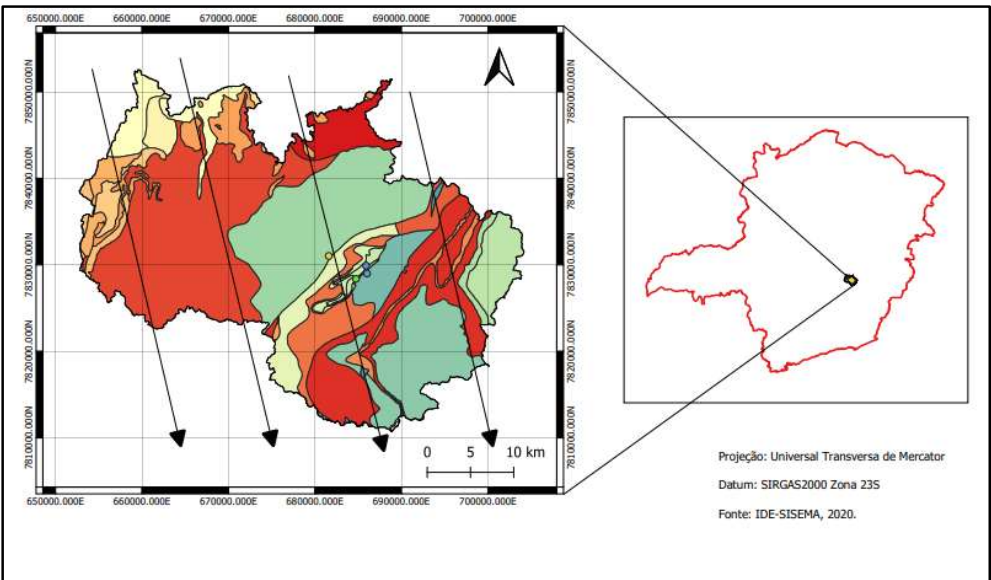

Figura 6: Classificação geológica do município de Itabira-MG.

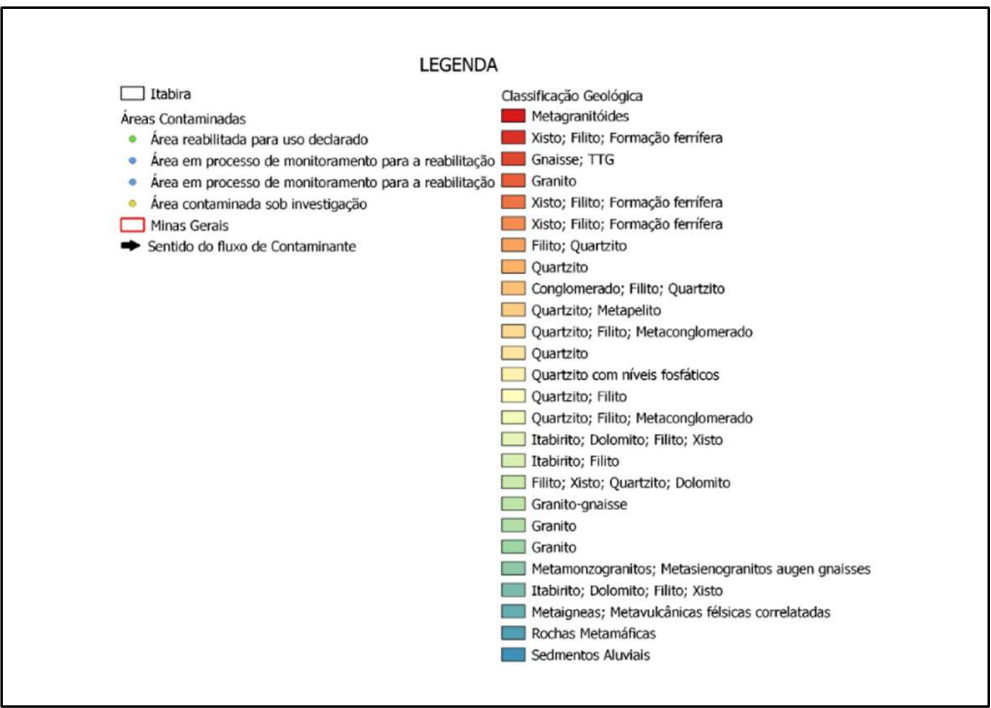

Figura 7: Legenda do mapa - Classificação geológica do município de Itabira-MG.

Através da classificação das rochas foi possível entender os tipos de solos encontrados nas áreas de estudo, como demonstrados por Kar (1997) que sugere que na região do Quadrilátero Ferrífero há grandes teores de óxidos de ferro, o que influencia na coloração e consequentemente na caracterização deste solo.

De acordo com a identificação da geologia das áreas contaminadas, as rochas presentes em tais áreas podem ser caracterizadas como rochas consolidadas, ou seja, rochas que possuem partículas de diferentes tamanhos e formas que foram solidificadas, seja por calor e pressão ou por reações químicas. Tal afirmação é importante para se determinar o tipo de aquífero presente na região, indicando que esses tipos de rochas num geral contêm aquíferos confinados, sendo aquíferos onde a pressão da água em seu topo é maior que a pressão atmosférica, e também como ocorre a possível comunicação entre a zona saturada e insaturada nessas regiões, possivelmente sucedendo através do fenômeno de capilaridade (MANOEL FILHO, 2008;

\footnotetext{
${ }^{3}$ Rochas ígneas são rochas que se formam pelo resfriamento e solidificação do magma (BRANCO, 2015)

${ }^{4}$ Rochas metamórficas são rochas que são formadas a partir de outras rochas, em decorrência da ação do metamorfismo (BRANCO, 2015) 
HEATH, 1982).

Levando em consideração a porosidade e a permeabilidade das rochas, que consiste na capacidade de reter água e na capacidade de transmitir água, respectivamente, no geral rochas ígneas e metamórficas possuem baixos valores de porosidade quanto de permeabilidade, indicando assim uma baixa comunicação com aquíferos adjacentes. Ainda é possível notar uma tendência da diminuição da permeabilidade com o aumento da profundidade (MANOEL FILHO, 2008).

Costa (2008) demonstra como se comporta a hidrogeologia em rochas ígneas e metamórficas. Tal fato, caracteriza-se pela inexistência ou presença muito reduzida de vazios entre os arranjos granulares, devido ao arranjo cristalino dessas rochas, o que demonstra que a água fica retida em espaços denominadas fraturas ou fissuras, ocasionando assim em um aquífero confinado ou fissural, o que torna os aquíferos presentes nas áreas estudadas mais protegidos.

Silva (2008) demonstra que para entender como o poluente se comporta no aquífero é necessário conhecer as características, físicas, químicas e biológicos de ambos. A propagação da pluma de contaminantes dependerá desses fatores bem como as formas de tratamentos.

Desta maneira, o que se espera é que, na região das áreas contaminadas, em decorrência das características físico-químicas dos solos, da porosidade e permeabilidade das rochas e do gradiente hidráulico, a dispersão dos poluentes seja atenuada nos Latossolos, e devido a litologia da área, os aquíferos confinados existentes sejam mais protegidos, diminuindo o risco de propagação dos contaminantes no meio.

\section{CONCLUSÕES}

Diante do panorama demostrado dentro no município de Itabira-MG, o presente trabalho observou que o risco de propagação de contaminantes e aumento da pluma de contaminação atualmente existente é baixo, em virtude: i) da ocorrência de solos com alta capacidade de adsorção de metais pesados e grande espessura, o que faz com que o poluente tenha que percorrer grandes distâncias até alcançar os aquíferos; ii) da geologia da área, que favorece a formação de aquíferos confinados e iii) da baixa velocidade da água subterrânea, o que dificulta a dispersão de poluentes para grandes distâncias da fonte de contaminação.

Ressalta-se que tais levantamentos foram realizados a partir de dados secundários, de modo que uma maior precisão nos estudos demanda análise de campo para a identificação de demais fatores determinantes na mensuração da propagação desses contaminantes.

\section{REFERÊNCIAS}

ABREU, C. A; ABREU, M. F.; ANDRADE, J. C.. Determinação de cobre, ferro, manganês, zinco, cádmio, cromo, níquel e chumbo em solos usando a solução DTPA em ph 7,3. In: RAIJ, V.. Análise química para avaliação da fertilidade de solos tropicais. Campinas: Instituto Agronômico, 2002.

ACCIOLY, A. M. A.; SIQUEIRA, J. O.. Contaminação química e biorremediação do solo. In: NOVAIS, R. F.; ALVARES, V. H.; SCHAEFER, C. E. G. R.. Tópicos em ciência do solo. Viçosa: SBCS, 2000. p.299-352.
ALLEONI, L. R. F.; IGLESIAS, C. S. M.; MELLO, S. C.; CAMARGO, O. A.; CASAGRANDE, J. C.; LAVORENTI, N. A.. Atributos do solo relacionados à adsorção de cádmio e cobre em solos tropicais. Acta Scienciarum. Agronomy, Maringá, v.27, n.4, p.729-737, 2005.

ANTENOR, S.; SZIGETHY L.. Resíduos sólidos urbanos no Brasil: desafios tecnológicos, políticos e econômicos. Centro de Pesquisa em Ciência, Tecnologia e Sociedade. IPEA, 2020.

AZEVEDO, F. S.. Estudo experimental das influências de 
tensões na permeabilidade de rochas produtoras de petróleo. Dissertação (Mestrado em Engenharia Civil) Pontifícia Universidade Católica do Rio de Janeiro, Rio de Janeiro, 2005

BALTAZAR, O. F. LOBATO, L. M.; REIS, L. B.; ACHTSCHIN, A. B.; BAARS, F. J.; TIMBÓ, M. A.; BERNI, G. V.; MENDONÇA, B. R. V.; FERREIRA, D. V.. Mapa Geológico Itabirana na escala 1:50.000 com nota explicativa. Projeto Geologia do Quadrilátero Ferrífero - Integração e Correção Cartográfica em SIG com nota explicativa. Belo Horizonte: Universidade Federal de Minas Gerais, 2005.

BERNARD, A. M.. Effects of heavy metals in the environment on human health in contaminated soils. Paris: INRA, 1997.

BRANCO, P. M.. Rochas. Geocientífico, Serviço Geológico do Brasil (CPRM), 2015.

BRASIL. Lei Federal n. 6.939 de 31 de agosto de 1981. Define a política nacional do meio ambiente. Brasília: DOU, 1981.

CAMARGO, O. A.; CASTRO, O. M.; VIEIRA, S. R.; QUAGGIO, J. A.. Alteração de atributos químicos do horizonte superficial de um Latossolo e um Podzólico com calagem. Sci. Agric. Piracicaba, v.54, p.1-2, 1997. DOI: http://doi.org/10.1590/S0103-90161997000100001

CELERE, M. S.; OLIVEIRA, A. S.; TREVILATO, T. M. B.; SEGURAMUNÕZ, S. I.. Metais presentes no chorume coletado no aterro sanitário de Ribeirão Preto, São Paulo, Brasil, e sua relevância para saúde pública. Cad. Saúde Pública, v.23, n.4 2007. DOI: http://doi.org/10.1590/S0102311X2007000400021

CELLIGOI, A.; SANTOS, M. M.; VIANA, T. R.. Análise e interpretação do gradiente hidráulico do aquífero freático em uma área na região sul de Londrina-PR. Geografia, Londrina, v.10, n.1, p.79-88, 2012.

CHIARANDA, H. S.. Volatilização de compostos btex em ambientes subsuperficiais contaminados com gasolina e etanol: comparação entre concentrações medidas e simuladas. Dissertação (Mestrado em Engenharia Ambiental) - Universidade Federal de Santa Catarina, Florianópolis, 2006.

CODEMIG; CPRM. Serviço Geológico do Brasil. Mapeamento geológico do estado de Minas Gerais. Infraestrutura de Dados Especiais - Sistema Estadual de Meio Ambiente e Recursos Hídricos, 2017.

COPAM; CERH-MG. Decreto Estadual de n.2 de 08 de setembro de 2010. Define o programa estadual de gestão de áreas contaminadas. 2010.

COSTA, W. D.. Hidrogeologia dos meios fissurados. In: Hidrogeologia: conceitos e aplicações. 2008. p.121-151.

CUSTANCE, S. R.; MCCAW, P. A.; KOPF, A. C.; SULLIVAN, M. J.. Environmental fate of the chemical mixtures: crude oil, jp5, mineral spirits, and diesel fuel. J. Soil Contam., v.1, p.379386, 1992.

COVELO, E. F.; VEGA, F. A.; ANDRADE, M. L.. Competitive sorption and desorption of heavy metals by individual soil components. Journal of Hazardous Materials, v.140, n.1-2, p.308-315, 2007.

EMBRAPA. Empresa Brasileira de Pesquisa Agropecuária. Sistema de classificação de solos brasileiros. 5 ed. Brasília: EMBRAPA, 2018

FEITOSA, F. A. C.; MANOEL FILHO, J.. Hidrogeologia: Conceitos e Aplicações. Fortaleza: Serviço Geológico do Brasil, 1997.

FOGAÇA, L. B. V.; MARTINS, B. F.; AMORIM, L. L. G.; ALMEIDA, F. P.. Comportamento da Percolação de Poluentes hidrocarbonetos em função da textura do solo. In: CONGRESSO BRASILEIRO DE GESTÃO AMBIENTAL, 5. Anais. Belo Horizonte, 2014

FRANCO, A.. Quadrilátero Ferrífero: preservação x mineração. Belo Horizonte: Minas Jr Consultoria Mineral, 2018.

FEAM. Fundação Estadual do Meio Ambiente. Inventário e lista de Áreas Contaminadas. Belo Horizonte: FEAM, 2020.

HEATH, R. C.. Basic ground-water hidrology. North Carolina depertament of natural resourses and Community development, 1982.

IBGE. Instituto Brasileiro de Geografia e Estatística. Censo Demográfico. IBGE, 2010.

KAR, J. C.. Latossolos do Brasil: Uma revisão. Geonomos, Revista do Centro de Pesquisa Professor Manoel Teixeira da Costa. Belo Horizonte: Universidade Federal de Minas Gerias, 1997.

LANGE, L. C.; SIMÕES, G. F.; FERREIRA, C. F. A.; COELHO, H. M. G.. Estudo do transporte de contaminantes em meios porosos aplicado a aterros de disposição de resíduos sólidos urbanos. In: CASTILHOS JUNIOR, A. B.; LANGE, L. C.; GOMES, L. P.; PESSIN, N.. Alternativas de disposição de resíduos sólidos para pequenas comunidades. Rio de Janeiro, 2002.

LEPSCH, I. F.. Formação e conservação dos solos. 2 ed. Oficina de textos, 2010.

LEPSCH, I. F.. 19 lições de pedologia. Oficina de textos, 2011.

MANOEL FILHO, J. M.. Ocorrência das Águas subterrâneas. In: Hidrogeologia: conceitos e aplicações. 2008. p.53-76.

MEAULO, F. J.. Vulnerabilidade natural à poluição dos recursos hídricos subterrâneos da área de Araraquara (SP). Dissertação (Mestrado) - Universidade Estadual Paulista, Rio Claro, 2004.

MECHI, A.; SANCHES, D. L.. Impactos ambientais da Mineração no estado de São Paulo. Estud. Av., v.24, n.68, 2010. DOI: http://doi.org/10.1590/S010340142010000100016

MEURER, E. J.. Fundamentos da química do solo. 6 ed. Porto Alegre, 2017.

NADIM, F.; HOAG, G. E.; LIU, S.; CARLEY, R. J.; ZACK, P.. Detection and remediation of soil and aquifer systems contaminated with petroleum products: an overview. J. of 
Petrol. Sci. and Eng., v.26, p.169-178, 1999.

NASS, D. P.. O conceito de Poluição. Revista eletrônica de ciências, v.1, n.13, 2002.

OLIVEIRA, S. H.. Avaliação do uso de borra oleosa processada em sistemas de impermeabilização de aterros. Tese (Doutorado em Engenharia Civil) - Pontifícia Universidade Católica do Rio de Janeiro, Rio de Janeiro, 2002.

OLIVEIRA, F. C.; MATTIAZZO, M. E.; MARCIANO, C. R.; ABREU JUNIOR, C. H.. Alterações em atributos químicos de um Latossolo pela aplicação de composto de lixo urbano. Pesquisa Agropecuária Brasileira, Brasília, v.37, n.4, p.529538,2002

PEREIRA, E.. Variação de fluxo na região envoltória dos poços tubulares em meio poroso: fatores que influenciam a produtividade. In: CONGRESSO BRASILEIRO DE ÁGUAS SUBTERRÂNEAS, 11. Anais. São Paulo, 2000.

PEREIRA, E. M.; CHANG, H. K.; SOTO, M. A. A.. Estimativa de alguns parâmetros de transporte de contaminantes para solos brasileiros. Rio Claro: UNESP, 2011.
SANTOS, M. M.. Avaliação hidrogeológica para a determinação natural do aquífero freático em área selecionada na cidade de Londrina (PR). Dissertação (Mestrado) - Instituto de Geociências e Ciências Exatas, Rio Claro, 2005.

SAAE. Serviço Autônomo de Água e Esgoto. Cadastros de poços na zona rural de Itabira-MG. Itabira: SAAE, 2020.

SILVA, A. B.. Hidrogeologia de Meio Cársticos. In: Hidrogeologia, conceitos e aplicações. 2008. p.161-165.

SILVEIRA, M. L. A.; ALLEONI, L. R. F.; GUILHERME, L. R. G.. Biosolids and heavy metal in soils. Scientia Agricola, v.60, p.793-806, 2003.

UFV; FEAM. Universidade Federal de Viçosa; Fundação Estadual do Meio Ambiente. Mapeamento pedológico do Estado de Minas Gerais. Infraestrutura de Dados Especiais Sistema Estadual de Meio Ambiente e Recursos Hídricos, 2017.

VALE. Memória da tecnologia da mineração em Itabira. VALE S.A., 2016.

A CBPC - Companhia Brasileira de Produção Científica (CNPJ: 11.221.422/0001-03) detém os direitos materiais desta publicação. Os direitos referem-se à publicação do trabalho em qualquer parte do mundo, incluindo os direitos às renovaç̃oes, expansões e disseminações da contribuiç̃o, bem como outros direitos subsidiários. Todos os trabalhos publicados eletronicamente poderão posteriormente ser publicados em coletâneas impressas sob coordenação da Sustenere Publishing, da Companhia Brasileira de Produção Científica e seus parceiros autorizados. Os (as) autores (as) preservam os direitos autorais, mas não têm permissão para a publicação da contribuição em outro meio, impresso ou digital, em português ou em tradução. 